\title{
Total column ozone retrieval using INSAT-3D sounder in the tropics: A simulation study
}

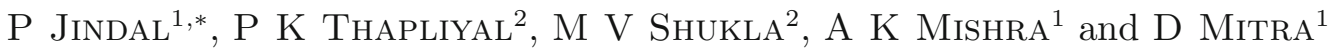 \\ ${ }^{1}$ Indian Institute of Remote Sensing, Dehradun 248 001, India. \\ ${ }^{2}$ Space Applications Centre, Ahmedabad 380 015, India. \\ *Corresponding author.e-mail: pooja_j@iirs.gov.in
}

The present study examines the potential of infrared sounder observations from Indian geostationary satellite INSAT-3D for the estimation of total column integrated ozone over the tropical Indian region. A dataset with diverse profiles was used to create training and testing datasets using forward simulations from a radiative transfer model for infrared sounder channels. A study was carried out for the standard tropical atmospheric profile to examine the sensitivity of ozone band radiance corresponding to the atmospheric temperature, water vapour, and ozone mixing ratios at different atmospheric pressure levels. Further, statistical retrieval technique has been used for the total column ozone estimation using two different approaches: (i) ozone channel observation along with the a-priori estimate of temperature and water vapour profile and (ii) only sounder channels observations. The accuracy of the retrieval algorithms was examined for different errors in the atmospheric profiles for the method (i) and different sensor noise specification for the method (ii). This study has shown that accurate temperature information is very important for ozone estimation and lower instrument noise results in better ozone estimates.

\section{Introduction}

Although ozone is a trace gas constituting of less than $0.001 \%$ of the air by volume, it plays an important role in sustaining life on Earth. The ozone layer in the stratosphere protects the biosphere by absorbing harmful solar ultraviolet radiation, although tropospheric ozone is regarded as a pollutant. Ozone is the main precursor of the highly reactive hydroxyl radical which is considered as a 'detergent' in troposphere. Therefore, a decrease in ozone concentration in stratosphere or increase in troposphere is regarded as undesirable (IPCC 2001). Nevertheless, in the present scenario tropospheric ozone is increasing and stratospheric ozone is decreasing. Therefore, interest in monitoring atmospheric ozone has increased and satellite instruments are playing a significant role for this purpose. The main satellite instruments used for monitoring ozone are the Total Ozone Mapping Spectrometer (TOMS) (Bowman and Krueger 1985, McPeters et al. 1996, 1998) and the Solar Backscatter Ultraviolet (SBUV) spectrometer (Heath et al. 1975). However, neither the TOMS nor the SBUV, which measure backscattered ultraviolet solar radiation, are capable of providing measurements at night. Infrared (IR) radiance measurements, since they do not depend on backscattered solar energy, can be used for ozone estimation for both day and night time. Other satellite instruments, such as the Global Ozone Monitoring Experiment (GOME) (Burrows et al. 1999; Anton et al. 2011), the SCanning Imaging Absorption spectroMeter for Atmospheric CHartographY (SCIAMACHY) (Anton et al. 2011), the Microwave Limb Sounder (MLS)

Keywords. INSAT-3D; sounder; retrieval; total ozone. 
(Livesay et al. 2006), the Stratospheric Aerosol and Gas Experiment (SAGE) (McCormick 1991), the Polar Ozone and Aerosol Measurement (POAM) (Bevilacqua 1997) and the Ozone Monitoring Instrument (OMI) (Liu et al. 2010) can also provide useful atmospheric ozone information.

The NOAA-TOVS (TIROS operational vertical sounder)/ATOVS (Advanced TIROS operational vertical sounder) could provide day and night time measurements of total column ozone in addition to atmospheric temperature and water vapour (Li et al. 1999). However, geostationary satellites are required for continuous monitoring of the atmospheric profiles. Among geostationary satellites, the Geostationary Operational Environmental Satellite (GOES) series of satellites carrying the IR sounder have provided high temporal resolution data over the US region since 1994 (Menzel and Purdom 1994; Li et al. 2001, 2007). Recently, the Indian Space Research Organisation (ISRO) has launched a meteorological satellite INSAT-3D carrying a 19-channel (18 channels are IR and 1 channel is visible) sounder along with other instruments which are providing continuous observation over the Indian region. The present study is based on simulated radiances for INSAT-3D sounder over tropical region. In this paper, initially the sensitivity of the sounder ozone band corresponding to standard tropical temperature, water vapour, and ozone profile has been analyzed. Later, an attempt has been made to develop statistical regression algorithm for total ozone retrieval over tropical region. In the present study, two algorithms have been developed. In the first algorithm, sounder ozone band along with temperature and water vapour profiles has been used while in the second algorithm the first 15 bands for the sounder were used for total ozone retrieval.

\section{Instrument characteristics}

The INSAT-3D sounder instrument has 18 IR channels ranging from 3.7 to $14.7 \mu \mathrm{m}$ and one visible channel. The IR channels are sensitive to atmospheric gases, primarily $\mathrm{CO}_{2}$ (Carbon-dioxide), $\mathrm{O}_{3}$ (Ozone) and $\mathrm{H}_{2} \mathrm{O}$ (water vapour). The detailed sounder IR channels characteristics along with the sensor noise are provided in table 1 .

\section{Sensitivity study of the sounder ozone band}

The perturbation method was used to study the sensitivity (weighting function) of the ozone band $(9.7 \mu \mathrm{m})$ corresponding to atmospheric temperature, water vapour mixing ratio, and ozone mixing ratio over the standard tropical region. This is similar to the sensitivity analysis done by $\mathrm{Li}$ et al. (2001) that was carried out for the GOES observation region using the US Standard atmospheric profile. As US standard atmosphere is cold and dry in contrast to hot and humid tropical Indian atmosphere, a separate sensitivity study of INSAT-3D sounder ozone band for the tropical profile has been carried out. The tropical profile used here is the mean of tropical profiles extracted from the atmospheric profiles generated at ECMWF by Marco Matricardi. The details of the profile dataset can be found in Matricardi (2008). The profiles were available at 101 pressure levels, which were interpolated to 43 pressure levels before use. The atmospheric profile at each level was perturbed by small amount, and the radiative transfer simulation was carried out to observe the corresponding change in the sounder ozone band radiance. The perturbation amount in the present study was assumed to be $10 \mathrm{~K}$ for atmospheric temperature, and $10 \%$ for the water vapour mixing ratio and ozone mixing ratio.

Figure 1 shows weighting functions for INSAT$3 \mathrm{D}$ sounder ozone band corresponding to atmospheric temperature, water vapour mixing ratio, and ozone mixing ratio for the Standard Tropical Atmosphere. It is apparent that the sounder ozone band is sensitive to both surface and stratospheric temperature; thus knowledge of surface and atmospheric temperature is important in estimating ozone information from the sounder ozone band. The weighting function for ozone mixing ratio shows notable sensitivity to the ozone band in the lower and lower-middle $(20-35 \mathrm{hPa})$ stratosphere. Although the lower stratosphere contains only half of the total column ozone, it is responsible for the bulk of the ozone variability. Since the INSAT-3D ozone band has less ozone sensitivity in the mid- and upper-stratosphere, it is less capable of detecting the ozone variability in this region. At around $2 \mathrm{hPa}$, ozone sensitivity is positive, i.e., with decrease in ozone fraction, radiation received by the sounder also decreases. This may be due to temperature inversion at this level. The sounder ozone band is also affected by water vapour absorption with sensitivity peak at about $750 \mathrm{hPa}$. These findings are consistent with those of Li et al. (2001).

\section{Total column ozone retrieval}

In this study, a statistical retrieval technique has been used for the total column ozone retrieval from sounder observations. A training dataset has been used to establish a relationship between input parameters (radiance/brightness temperature) and parameters to be retrieved (atmospheric profiles). 
Table 1. INSAT-3D sounder IR channels characteristics.

\begin{tabular}{|c|c|c|c|c|c|}
\hline $\begin{array}{l}\text { Channel } \\
\text { no. }\end{array}$ & $\begin{array}{c}\text { Central wavelength } \\
\qquad \mu \mathrm{m}\left(\mathrm{cm}^{-1}\right)\end{array}$ & $\begin{array}{l}\mathrm{FWHM}^{*} \mu \mathrm{m} \\
\left(\mathrm{cm}^{-1}\right)\end{array}$ & $\begin{array}{l}\text { Instrument noise at } \\
300 \mathrm{~K}(\mathrm{NEdT})(\mathrm{K})\end{array}$ & $\begin{array}{c}\text { Principal } \\
\text { absorbing gas }\end{array}$ & Purpose \\
\hline 1 & $14.71(680)$ & $0.281(13)$ & 1.5 & $\mathrm{CO}_{2}$ & Stratosphere temperature \\
\hline 2 & $14.37(696)$ & $0.268(13)$ & 1 & $\mathrm{CO}_{2}$ & Tropopause temperature \\
\hline 3 & $14.06(711)$ & $0.256(13)$ & 0.5 & $\mathrm{CO}_{2}$ & Upper-level temperature \\
\hline 4 & $13.96(733)$ & $0.298(16)$ & 0.5 & $\mathrm{CO}_{2}$ & Mid-level temperature \\
\hline 5 & $13.37(749)$ & $0.286(16)$ & 0.5 & $\mathrm{CO}_{2}$ & Low-level temperature \\
\hline 6 & $12.66(790)$ & $0.481(30)$ & 0.3 & $\mathrm{H}_{2} \mathrm{O}$ & Total precipitable water \\
\hline 7 & $12.02(832)$ & $0.723(50)$ & 0.15 & $\mathrm{H}_{2} \mathrm{O}$ & Surface temperature, moisture \\
\hline 8 & $11.03(907)$ & $0.608(50)$ & 0.15 & Window & Surface temperature \\
\hline 9 & $9.71(1030)$ & $0.235(25)$ & 0.2 & Ozone & Total ozone \\
\hline 10 & $7.43(1425)$ & $0.304(55)$ & 0.2 & $\mathrm{H}_{2} \mathrm{O}$ & Low-level moisture \\
\hline 11 & $7.02(1425)$ & $0.394(80)$ & 0.2 & $\mathrm{H}_{2} \mathrm{O}$ & Mid-level moisture \\
\hline 12 & $6.51(1535)$ & $0.255(60)$ & 0.2 & $\mathrm{H}_{2} \mathrm{O}$ & Upper-level moisture \\
\hline 13 & $4.57(2188)$ & $0.048(23)$ & 0.2 & $\mathrm{~N}_{2} \mathrm{O} * *$ & Low-level temperature \\
\hline 14 & $4.52(2210)$ & $0.047(23)$ & 0.15 & $\mathrm{~N}_{2} \mathrm{O}$ & Mid-level temperature \\
\hline 15 & $4.45(2245)$ & $0.045(23)$ & 0.15 & $\mathrm{CO}_{2}$ & Upper-level temperature \\
\hline 16 & $4.13(2420)$ & $0.0683(40)$ & 0.15 & $\mathrm{CO}_{2}$ & Boundary level temperature \\
\hline 17 & $3.98(2513)$ & $0.0683(40)$ & 0.15 & Window & Surface temperature \\
\hline 18 & $3.74(2671)$ & $0.140(100)$ & 0.15 & Window & Surface temperature, moisture \\
\hline
\end{tabular}

*Full width at half maxima; ** Nitrous oxide.

Source: http://122.252.237.243/Missions/insat-3d/sounder.jsp

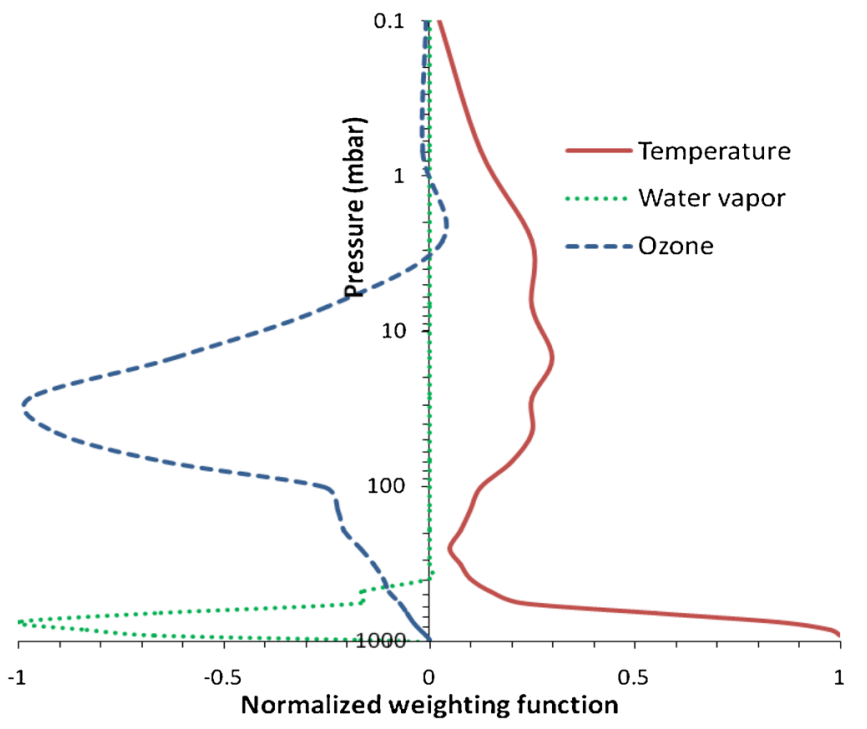

Figure 1. Atmospheric temperature, water vapour and ozone mixing ratio component weighting functions for INSAT-3D sounder ozone band over tropical region.

The training dataset comprising of radiosonde observations should be collocated with satellite observations in space and time. However, it is difficult and time consuming to find the properly collocated large training dataset due to differences in the spatial and temporal sampling of the satellite and in-situ observations in clear sky conditions. Alternatively, a synthetic dataset can be used. In the present study, a radiative transfer model has been used to simulate the sounder radiances with suitable instrument noise added to it.

Regression coefficients $(B)$ between atmospheric parameters, $X$ (parameter to be retrieved, e.g., temperature, water vapour or total column ozone) and sounder observations, $Y$ (input parameter, i.e., brightness temperatures) can be computed at different viewing angles from simulated training dataset using

$$
B_{l \times m}=(d X)_{l \times n}(d Y)_{m \times n}^{T}\left[(d Y)_{m \times n}(d Y)_{m \times n}^{T}\right]^{-1}
$$

where $n$ is the number of training profiles used for generation of regression coefficients; $m$ is the number of observations/channels used, and $l$ is the number of output retrieved parameters. Here, $d X=X-X_{\text {mean }}$, and $d Y=Y-Y_{\text {mean }}$, where $X_{\text {mean }}$ and $Y_{\text {mean }}$ are average of $X$ and $Y$ over all training profiles. Superscript ' $T$ ' is used to indicate transpose of the matrix.

These regression coefficients can be used to retrieve the atmospheric parameters using the following relation

$$
X_{\text {ret }}=X_{\text {mean }}+B(d Y)_{\mathrm{obs}}^{T}
$$

where $d Y_{\mathrm{obs}}=Y_{\mathrm{obs}}-Y_{\text {mean }}$; here $Y_{\mathrm{obs}}$ is the matrix of predictors (observed brightness temperature) used to retrieve the predictand matrix $X_{\text {ret }}$. 


\subsection{Dataset and radiative transfer model}

To demonstrate the performance of retrieval method, the simulated dataset of INSAT-3D sounder channels using the fast radiative transfer model RTTOV-9 (Eyre 1991; Eyre and Woolf 1988; Saunders et al. 1999) developed by the European Center for Medium Range Weather Forecast (ECMWF) has been used. RTTOV-9 uses the Pressure Layer Optical Depth algorithm (Matricardi et al. 2001) for radiative transfer calculation. Radiance (brightness temperature) calculations are done at 43 pressure levels ranging from 1013 to 0.1 $\mathrm{hPa}$, taking into account the observational zenith angle and the absorption by well-mixed gases, water vapour, and ozone. Clear-sky radiances, simulated for nadir looking observations, were used in this study. In order to account for the measurement noise, a Gaussian-distributed random number with zero mean and standard deviation $\sigma$ (instrument noise) was added to the simulated radiances. Sounder channels brightness temperatures are simulated for the SeeBor dataset version 5.1 (SeeBorV5.1) comprising of about 15000 diverse global profiles of temperature, water vapour, and ozone (Borbas et al. 2005). These profiles were taken from NOAA-88, an ECMWF 60L training set, TIGR3 (TOVS Initial Guess Retrieval), ozonesonde from NOAA Climate Monitoring and Diagnostics Laboratory (CMDL) sites, and radiosonde for the year 2004 over the Sahara desert. Atmospheric profiles $(N=7600)$ over the tropical region $\left(45^{\circ} \mathrm{S}-45^{\circ} \mathrm{N}\right)$, with condition of surface pressure greater than 980 $\mathrm{hPa}$ to exclude mountains, were selected from this dataset to represent the atmosphere as viewed by the INSAT-3D. The retrieval algorithm was trained with about $80 \%$ of these profiles $(N=6080)$. The remaining $20 \%$ of the profiles were used for testing the algorithms.

Two different approaches to regression retrieval for total column ozone from the sounder observations as discussed by Li et al. (2001) are examined in the following sections.

\subsection{Total ozone estimation from the sounder ozone band radiance, atmospheric temperature and water vapour profiles (1st algorithm)}

To analyze the influence of atmospheric temperature and moisture on ozone estimation from INSAT-3D ozone band, the following relationship was generated for total column ozone estimation

$$
\begin{aligned}
\text { TCO }= & A_{0}+A_{1} T_{b_{9}}+A_{2} T_{b_{9}}^{2}+B_{0} T_{s} \\
& +\sum_{i=1}^{i=43} B_{i} T_{i}+\sum_{i=1}^{i=43} C_{i} \ln q_{i}
\end{aligned}
$$

where TCO is the total column ozone value in Dobson units (DU); $T_{b_{9}}$ is the brightness temperature corresponding to channel \#9 (ozone band) of the sounder; $T_{s}$ is the surface temperature; $T_{i}$ and $q_{i}$ are the atmospheric temperature and water vapour mixing ratio at $i$ th atmospheric level; and $A, B, C$ are the regression coefficients. For the realtime INSAT-3D sounder observations, the temperature and water vapour profiles can be used from the Numerical Weather Prediction (NWP) model analysis/forecast to retrieve the total column ozone. To estimate the impact of errors in the input profiles from NWP forecast, the following three scenarios were studied.

- The atmospheric temperature profile, surface skin temperature, and atmospheric moisture profile are assumed to be unknown in the regression. This is achieved by using only the first three terms in equation (3), i.e., only the INSAT$3 \mathrm{D}$ sounder ozone band radiance is used as predictor.

- The atmospheric temperature profile and surface skin temperature are assumed to be known, but the atmospheric moisture profile is assumed to be unknown. In this case, the first five terms of equation (3) are used with the atmospheric and surface skin temperatures as additional predictors. The error in surface skin temperature and temperature profile at each atmospheric level is assumed constant. This configuration, studies the impact of the temperatures profile on the total ozone estimates by varying the temperature error from 0.5 to $3.5 \mathrm{~K}$.

- The atmospheric temperature profile and surface skin temperature are assumed to be unknown by using only the first three and the last terms in equation (3), but the atmospheric moisture profile is assumed to be known. The water vapour mixing ratios are used as additional predictors in equation (3), and it is assumed that the error for water vapour mixing ratios is constant at each atmospheric level. This configuration studies the impact of atmospheric moisture on the total ozone estimates by varying the moisture error from $5 \%$ to $20 \%$.

Regression coefficients in equation (3) were computed for each configuration. The outcomes of the above study are as follows:

\subsubsection{Impact of temperature profile}

Table 2 lists the \%RMSE (percentage root mean square error) of total ozone estimates from configuration (i) and (ii). From row nos. 9 and 1, it is clear that \%RMSE for TCO estimation improves by factor of approximately 2.0 with addition of 
Table 2. \%RMSE of total ozone estimates with temperature error varying from 0.5-3.5 K (instrument noise is taken as NEdT; $T$ is temperature; $q$ is water vapour).

\begin{tabular}{llc}
\hline Sl. no. & \multicolumn{1}{c}{$\begin{array}{c}\text { Atmospheric } \\
\text { prior information }\end{array}$} & $\begin{array}{c}\text { RMSE of total } \\
\text { ozone estimates (\%) }\end{array}$ \\
\hline 1 & $T$ known; $q$ unknown & 5.01 \\
2 & $T$ known with $0.5-\mathrm{K}$ error; $q$ unknown & 5.09 \\
3 & $T$ known with 1.0-K error; $q$ unknown & 5.24 \\
4 & $T$ known with $1.5-\mathrm{K}$ error; $q$ unknown & 5.43 \\
5 & $T$ known with $2.0-\mathrm{K}$ error; $q$ unknown & 5.63 \\
6 & $T$ known with $2.5-\mathrm{K}$ error; $q$ unknown & 5.83 \\
7 & $T$ known with $3.0-\mathrm{K}$ error; $q$ unknown & 6.02 \\
8 & $T$ known with 3.5-K error; $q$ unknown & 6.19 \\
9 & $T$ unknown; $q$ unknown & 9.06 \\
\hline
\end{tabular}

Table 3. \%RMSE of total ozone estimates with water vapour error varying from $5 \%$ to $20 \%$.

\begin{tabular}{llc}
\hline Sl. no. & \multicolumn{1}{c}{$\begin{array}{c}\text { Atmospheric } \\
\text { prior information }\end{array}$} & $\begin{array}{c}\text { RMSE of total } \\
\text { ozone estimates (\%) }\end{array}$ \\
\hline 1 & $T$ known; $q$ unknown & 8.70 \\
2 & $T$ unknown; $q$ known with $5 \%$ error & 8.68 \\
3 & $T$ unknown; $q$ known with 10\% error & 8.72 \\
4 & $T$ unknown; $q$ known with 15\% error & 8.75 \\
5 & $T$ unknown; $q$ known with 20\%error & 8.78 \\
6 & $T$ unknown; $q$ unknown & 9.06 \\
\hline
\end{tabular}

(Instrument noise taken is NEdT; $T$ is temperature; $q$ is water vapour).

accurate temperature information in the retrieval algorithm. Also the \%RMSE increases approximately by $1.0 \%$ as the temperature error increases from 0.5 to $3.5 \mathrm{~K}$. This strong correlation between temperature and ozone estimates implies that a precise knowledge of temperature is very important for TCO retrieval from sounder ozone band observations. This is due to the fact that the temperature sensitivity is significantly higher at the level of peak ozone concentration (stratosphere) as seen in figure 1.

\subsubsection{Impact of water vapour}

Table 3 lists the \%RMSE of total ozone estimates from configurations (i) and (iii). It shows a small sensitivity to moisture in the ozone estimation. The \%RMSE exhibits a change of about $0.10 \%$ as water vapour error is increased from $5 \%$ to $20 \%$. Also the \%RMSE of ozone estimates improves only by $0.36 \%$ with water vapour information as is clear from row nos. 6 and 1 . So, it can be inferred that only a general a-priori moisture profile is needed for ozone estimates from the sounder ozone band. This is due to the fact that the water vapour sensitivity is a maximum in the mid-troposphere where ozone variation/sensitivity is small and has negligible sensitivity in the stratosphere.

\subsubsection{Impact of instrument noise}

To account for effect of instrument noise, configuration (ii) with temperature error of $2 \mathrm{~K}$ is used. It is because the RMSE error of temperature profile from GOES sounder and NOAA-ATOVS is about $2 \mathrm{~K}$ (Li et al. 1999; Reale et al. 2008). Table 4 shows the \%RMSE of total ozone estimates with different level of instrument noise. The table shows that with increase in instrument noise, \%RMSE also increases.

\subsection{Total ozone estimation from the sounder band radiances (2nd algorithm)}

Temperature and moisture profiles as well as the surface temperature can be inferred from a combination of INSAT-3D $\mathrm{CO}_{2}$ spectral bands and water vapour bands. To account for the atmospheric temperature, moisture, and surface skin temperature effects, an empirical relationship of INSAT-3D sounder radiances against TCO is used

$$
\begin{aligned}
& \mathrm{TCO}=D_{0}+\sum_{j=1}^{j=15} D_{j} T_{b_{j}}+\sum_{j=1}^{j=15} D_{j}^{\prime} T_{b_{j}}^{2} \\
& +E_{1} p_{s}+E_{2} \cos \left(\frac{M-6}{12} \pi\right)+E_{3} \cos (\mathrm{LAT})
\end{aligned}
$$


Table 4. \%RMSE of total ozone estimates with different levels of instrument noise ( $q$ unknown; T known with $2.0 \mathrm{~K}$ error) using 1st algorithm.

\begin{tabular}{lcc}
\hline Sl. no. & $\begin{array}{c}\text { Instrument } \\
\text { noise }\end{array}$ & $\begin{array}{c}\text { RMSE of total } \\
\text { ozone estimates }(\%)\end{array}$ \\
\hline 1 & $2.0 * \mathrm{NEdT}$ & 5.66 \\
2 & $1.5 * \mathrm{NEdT}$ & 5.65 \\
3 & $1.0 * \mathrm{NEdT}$ & 5.63 \\
4 & $0.5 * \mathrm{NEdT}$ & 5.62 \\
\hline
\end{tabular}

Table 5. \%RMSE of total ozone estimates with different levels of instrument noise using 2nd algorithm.

\begin{tabular}{lcc}
\hline Sl. no. & Instrument noise & $\begin{array}{c}\text { RMSE of total } \\
\text { ozone estimates }(\%)\end{array}$ \\
\hline 1 & $2.0 * \mathrm{NEdT}$ & 4.68 \\
2 & $1.5 * \mathrm{NEdT}$ & 4.49 \\
3 & $1.0 * \mathrm{NEdT}$ & 4.34 \\
4 & $0.5 * \mathrm{NEdT}$ & 4.21 \\
\hline
\end{tabular}

where $D_{0}, D_{j}, D_{j}^{\prime}, E_{1}, E_{2}$, and $E_{3}$ are the regression coefficients; $T_{b_{j}}$ is brightness temperature corresponding to $j$ th channel of the sounder; $p_{s}$ is surface pressure; $M$ is month from 1 to 12 ; LAT is latitude and $j$ is INSAT-3D sounder band index. In this analysis, first 15 INSAT-3D sounder spectral band radiances has been used as the primary predictors. The previous studies have shown that the accuracy of ozone estimates using 15 IR spectral bands is better than using fewer spectral bands. Month and latitude are included as additional predictors in the regression because mid-stratospheric ozone is a complex function of latitude, season and temperature.

Table 5 provides the values of \%RMSE of total ozone estimates with different level of instrument noise using 2nd algorithm (equation 4). It is clear that \%RMSE decreases with decrease in instrument noise. On comparing tables 4 and 5 , one can notice that 2nd algorithm (equation 4) is much more sensitive to instrument noise as compared to 1 st algorithm (equation 3). This is because 2 nd algorithm uses 15 sounder channels as compared to only single channel used in 1st algorithm. The second point of importance is that 2nd algorithm gives better estimates for total column ozone as compared to 1st algorithm as \%RMSE for TCO retrieval is more in case of 1 st algorithm.

\section{Conclusions}

From sensitivity study of sounder ozone band, it has been noticed that the sounder's capability to detect ozone in lower and lower-mid stratosphere is higher as compared to mid and upper stratosphere. Moreover, the information of surface and atmospheric temperature is very important for total column ozone retrieval from sounder ozone band.

\%RMSE for total column ozone estimation using 1st algorithm (equation 3) shows that accurate temperature information significantly improves the retrieval accuracy and water vapour information improves the accuracy to some extent. However, it was found that 2 nd algorithm (equation 4 ) gives better ozone estimates. It has also been observed that lower the instrument noise, lesser the \%RMSE for total ozone retrieval.

Radiance data of INSAT-3D sounder can be used to retrieve the total column ozone. For algorithm 1 , temperature and water vapour profile may be taken from NWP models analysis or forecast.

\section{Acknowledgements}

The authors would like to thank Dr P S Roy, Previous Director IIRS; Dr Y V N Krishnamurthy, Director IIRS and Dr R R Navalgund, Previous Director SAC, for their constant encouragement. Authors thankfully acknowledge Eva E Borbas and Suzanne Wetzel Seemann, University of Wisconsin-Madison for creating SeeBor dataset. Authors are also thankful to RTTOV model team. The authors express their deep gratitude to the three anonymous referees for their valuable comments and suggestions. Thanks are also due to Dr Vaibhav Garg, Scientist IIRS, for helping in improving the presentation of the manuscript.

\section{References}

Anton M, Kroon M, Lopez M, Vilaplana J M, Banon M, Van der A R, Veefkind J P, Stammes P and Alados-Arboledas L 2011 Total ozone column derived from GOME and SCIAMACHY using KNMI retrieval algorithms: Validation against Brewer measurements at the Iberian Peninsula; J. Geophys. Res. 116(D22), doi: 10.1029/2011JD016436.

Bevilacqua R M 1997 Introduction to special section: Polar Ozone and Aerosol Measurement (POAM II); J. Geophys. Res. 102 23,591-23,592.

Borbas E S, Seemann H L, Huang J Li and Menzel W P 2005 Global profile training database for satellite regression retrievals with estimates of skin temperature and emissivity; Proceeding of International ATOVS Study Conference 14, 25-31 May 2005, Beijing, China pp. 763-770.

Bowman K P and Krueger A J 1985 A global climatology of total ozone from the Nimbus-7 total ozone mapping spectrometer; J. Geophys. Res. 90 7967-7976.

Burrows J P and Coauthors 1999 The Global Ozone Monitoring Experiment (GOME): Mission concept and first scientific results; J. Atmos. Sci. 56 151-175.

Eyre J R 1991 A fast radiative transfer model for satellite sounding system; Eur. Centre Medium-Range Weather Forecast., Reading, U.K., Tech. Memo. 176. 
Eyre J R and Woolf H M 1988 Transmittance of atmospheric gases in the microwave region: A fast model; Appl. Optics $273244-3249$.

Heath D F, Krueger A J, Roeder H A and Henderson B D 1975 The solar backscatter ultraviolet and total ozone mapping spectrometer (SBUV/TOMS) for NIMBUS G; Opt. Eng. 14 323-331.

Intergovernmental Panel on Climate Change (IPCC) 2001 Climate Change 2001: Contribution of Working Group I to the Third Assessment Report (eds) Houghton J T et al. (New York: Cambridge University Press), 881p.

Li J, Wolf W W, Menzel W P, Zhang W, Huang H and Achtor T H 1999 Global soundings of the atmosphere from ATOVS measurements: The algorithm and validation; J. Appl. Meteor. 39 1248-1268.

Li J, Schmidt C C, Nelson J P, Schmit T J and Menzel W P 2001 Estimation of total ozone from GOES sounder radiances with high temporal resolution; J. Atmos. Oceanic Technol. 18 157-168.

Li J, Li J, Schmidt C C, Nelson J P and Schmit T J 2007 High temporal resolution GOES sounder single field of view ozone improvements; Geophys. Res. Lett. 34 L01804, doi: 10.1029/2006GL028172.

Liu X, Bhartia P K, Chance K, Spurr R J D and Kurosu T P 2010 Ozone profile retrievals from Ozone Monitoring Instrument; Atmos. Chem. Phys. 10 2521-2537.

Livesay N J, Snyder W V, Read W G and Wagner P A 2006 Retrieval algorithms for the EOS Microwave Limb Sounder (MLS); J. Geosci. Remote Sens. 44(5) 13671379 .
Matricardi M 2008 The generation of RTTOV regression coefficients for IASI and AIRS using a new profile training set and a new line-by-line database; ECMWF Technical Memorandum No. 564.

Matricardi M, Chevallier F and Tjemkes S 2001 An improved general fast radiative transfer model for the assimilation of radiance observations; $E C M W F, E C M W F$ Res. Dept., Tech. Memo. 345.

McCormick M P 1991 SAGE III capabilities and global change; 29th Aerospace Sciences Meeting, Paper 91-0051, Reno, Nevada, American Institute of Aeronautics and Astronautics, 8p.

McPeters R D and Coauthors 1996 Nimbus-7 Total Ozone Mapping Spectrometer (TOMS) data products users guide; NASA Reference Publication 1384; National Aeronautics and Space Administration, Washington DC, 67p.

McPeters R D and Coauthors 1998 Earth Probe Total Ozone Mapping Spectrometer (TOMS) data products users guide; NASA Tech. Paper 206895; National Aeronautics and Space Administration, Washington DC, 72p.

Menzel W P and Purdom J F W 1994 Introducing GOES-I: The first of a new generation of geostationary operational environmental satellites; Bull. Am. Meteor. Soc. 75 757-781.

Reale A, Tilley F, Ferguson M and Allegrino 2008 A NOAA operational sounding products for advanced TOVS; Int. J. Remote Sens. 29(16) 4615-4651.

Saunders R W, Matricardi M and Brunel P 1999 An improved fast radiative transfer model for assimilation of satellite radiance observations; Quart. J. Roy. Meteor. Soc. 125(556) 1407-1425. 